\title{
AN ANALYTICAL REVIEW OF SPONTANEOUS HAEMOPNEUMOTHORAX
}

\author{
BY \\ R. J. CALVERT AND ERIC SMITH \\ From the Medical Unit, Whipps Cross Hospital, London
}

(RECEIVED FOR PUBLICATION SEPTEMBER 3, 1954)

In 1900 Newton Pitt wrote, "There is no reference to spontaneous haemopneumothorax in the Index Catalogue of the U.S. Library, nor is it discussed in any of the standard treatises on medicine, in either English, French, or German." It has remained little discussed even in specialized textbooks although about 150 cases, including the present three, have been recorded. Both spontaneous haemopneumothorax and spontaneous. haemothorax are complications of spontaneous pneumothorax, of which careful follow-up (Kjaergaard, 1932 ; Perry, 1939) has failed to reveal any correlation with tuberculosis. It is also probable that spontaneous haemothorax may at times have no coexistent or immediately antecedent spontaneous pneumothorax.

Both Pitt (1900) and Rolleston (1900) realized that spontaneous haemopneumothorax was potentially serious. Each reported a fatal case. Noteworthy contributions to this subject include those of Hyde and Hyde (1951) with 12 case reports, Ross (1952) with six, Louria (1938) with five, Moser (1951) with four, and Hopkins (1937), Hartzell (1942), Hansen (1949), Harrell (1949), Nalls and Matthews (1949), Rottenberg and Golden (1949), Eidinger and Rubin (1952), and Borrie (1953) each recording three cases. This subject has been briefly reviewed (Jones and Gilbert, 1936 ; Hopkins, 1937 ; Hartzell, 1942 ; Helwig and Schmidt, 1947 ; Nario, Bermúdez, and Espasandin, 1949 ; Deucher, 1950 ; Fusia and Cook, 1952; and Eidinger and Rubin, 1952). Some authors (Hartzell, 1952; Helwig and Schmidt, 1947; Cuningham, 1950) have also analysed available necropsy data. The literature indicates an overall mortality rate of $15 \%$, although a figure of $25 \%$ has been determined previously (Myers, Johnston, and Bradshaw, 1951 ; Ross, 1952). All these fatality rates are undoubtedly artificially high as the more serious or fatal cases are specially reported, while the milder cases are frequently unrecognized or unrecorded. Most of the fatalities have been relatively immediate. occurring in the first two days.
Only 10 cases (Hopkins, 1937 ; Hartzell, 1942 ; Crimm, 1948 ; Dorset and Terry, 1949 ; Deucher, 1949 ; Hansen, 1949 ; Harrell, 1949 ; Knight and Oelrich, 1949 ; Freund and Hicks, 1953 ; Towson, 1954) have been reported in women. Both sides of the chest have been equally involved. Recurrence is quite exceptional, but has been authenticated (Repetti, 1940; Rusby, 1947), while an earlier or later spontaneous pneumothorax has occasionally been described (Rist and Worms, 1940 ; Hartzell, 1942 ; Goldman and Roth, 1944 ; Deucher, 1950).

Our three illustrative cases, treated in the past two years, refute its rarity. Chapman (1950) claimed that, in spontaneous pneumothorax, free intrapleural haemorrhage occurs at the onset of pulmonary collapse in about one in eight patients. This frequency is not evident in the larger series of spontaneous pneumothorax. Rottenberg and Golden (1949), for instance, reported that three of 97 consecutive cases of simple pneumothorax had massive haemothorax from which one died, while Hyde and Hyde (1951), in a similar series of 112 cases, found that five of these patients had spontaneous haemopneumothorax.

This condition ranks with other forms of internal haemorrhage as a strict emergency. Indeed, our third patient died while too ill for exploratory thoracotomy.

\section{CASE Reports}

CASE 1.-J. H., a previously healthy clerk aged 26 , was admitted on May 28, 1952, with moderate breathlessness and a sharp inspiratory pain, radiating from the left lower chest behind the left shoulder. This pain had appeared abruptly on the previous evening while he was walking home from work. Despite distress, he reached home unaided and immediately went to bed. He experienced discomfort on attempting to lie on either side. Next morning he had several syncopal attacks, during one of which he was unconscious for five minutes. As movement increased his pain, he remained stock-still. His doctor diagnosed a left-sided pneumothorax, but considered that there was associated acute intercostal fibrositis 
as the intercostal muscles splinted the left hemithorax. The past history disclosed no respiratory disease. Indeed, a routine chest radiograph carried out three months previously was normal. There was no family history of tuberculosis.

Examination revealed a pale, anxious patient of fairly good physique with minimal venous congestion. The respirations were shallow and their rate was 30 per minute. The salient signs were confined to the respiratory and cardiovascular systems. The trachea was displaced to the right. The remaining respiratory signs were on the left side, where there was fullness, greatly restricted movement, and a very dull percussion note in the base, mid-zone, and axilla. In these sites tactile vocal fremitus, breath-sounds, and vocal resonance were absent, but aegophony was heard both in the scapular region and anteriorly. The vascular signs included tachycardia (120/minute), an easily compressible but regular pulse, and hypotension $(115 / 70 \mathrm{~mm}$. $\mathrm{Hg})$. The apex beat could not be located, while the cardiac sounds were pure but faint.

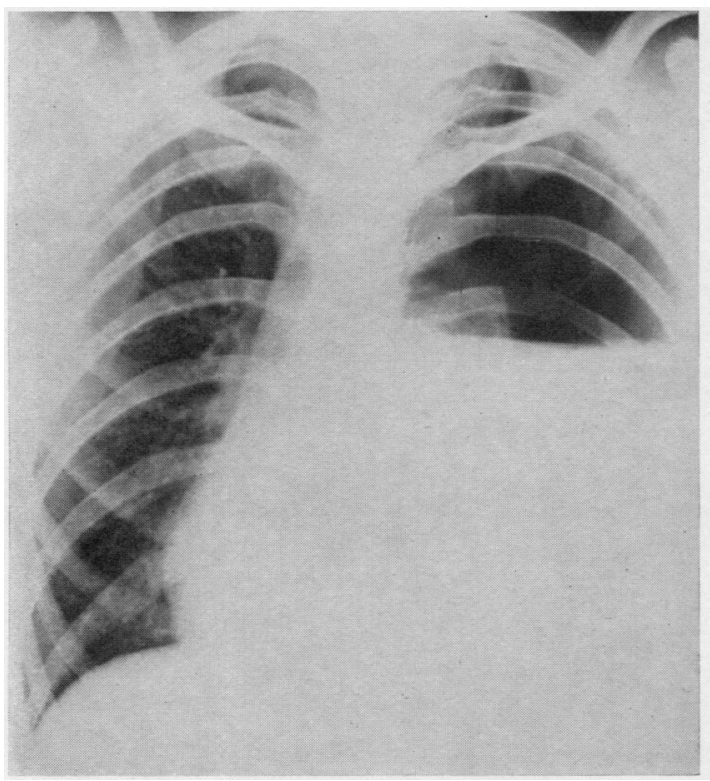

Fig. 1.-Case 1. Radiograph on May 28, 1952, on admission to hospital. Large left-sided pleural effusion before thoracentesis.

Immediate investigation showed a haemoglobin level of $56 \%$ with a normal total and differential white cell count, and a chest radiograph (Fig. 1) revealing a left-sided pneumothorax with effusion and ipsilateral apical pleural thickening. The electrocardiogram was normal apart from ST segment depression in the limb leads, suggesting a relative coronary insufficiency. An hourly pulse chart was begun and blood was crossmatched for emergency. Morphine sulphate ( $\frac{1}{4}$ gr.) was injected before thoracentesis, which yielded $5 \frac{1}{4}$ pints of sanguineous fluid with a haemoglobin value of $62 \%$. Almost complete re-expansion of the lung promptly followed. The next day the patient was

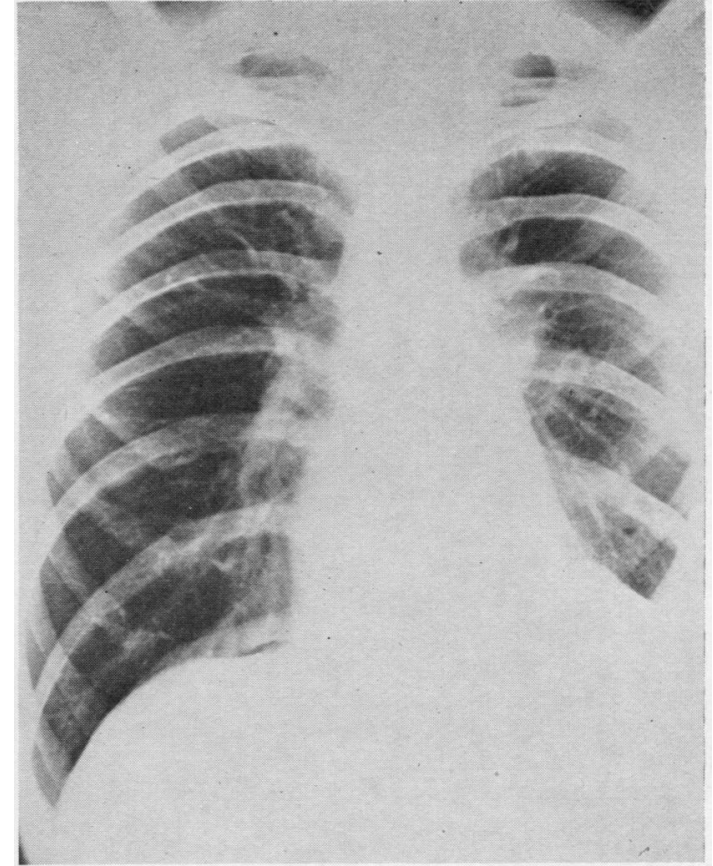

FIG. 2.-Case 1. Radiograph on June 16, 1952. Almost three weeks after the single aspiration of $5 \frac{1}{4}$ pints of haemorrhagic effusion. The left dome of the diaphragm is raised and a small effusion persists.

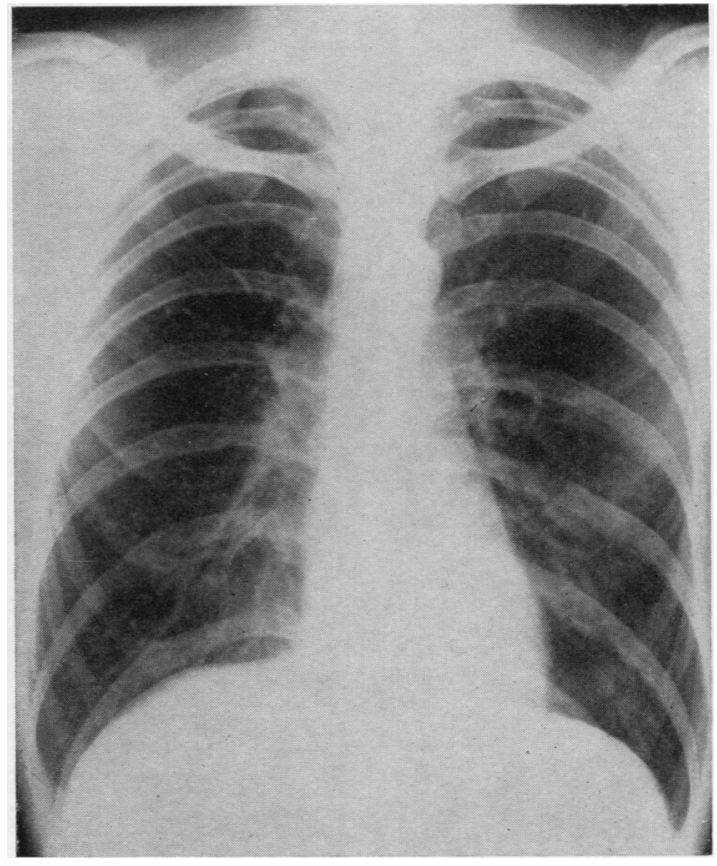

Fig. 3.-Case 1. Radiograph on January 8, 1953, six months after leaving hospital. Lung fields now normal apart from cystic disease in the left mid-zone. 
very comfortable with a pulse rate of 90 per minute, blood pressure of $115 / 75 \mathrm{~mm}$. $\mathrm{Hg}$, and the trachea central. Progress was now uneventful and the chest radiograph of June 16, 1952 (Fig. 2), was almost normal. Five weeks after admission he was discharged home feeling fit, having gained $8 \mathrm{lb}$. in weight, and with a haemoglobin value of $84 \%$ following treatment with ferrous sulphate $(0.2 \mathrm{~g}$.), ascorbic acid (50 mg.), and "casilan" (15 g.) each thrice daily. No blood transfusion was given throughout.

Two months later he returned to work, having gained a further $7 \mathrm{lb}$. in weight. He has since been followed up as an out-patient at three-monthly intervals. The E.S.R.s and chest radiographs, apart from cystic disease in the left mid-zone (Fig. 3), have remained normal. There has been no evidence of tuberculosis, including examination of the sanguineous fluid directly and on culture.

CASE 2.-J. G., a robust foundry-worker, aged 29, was admitted here on August 8, 1952, with a history that 10 days previously he experienced a sudden severe pain in the left side of the chest, especially posteriorly, but also felt in the left upper abdomen. He remained in bed under his doctor's supervision. The pain subsided after one day, but four days before admission it recurred with its previous severity. It was aggravated by deep breathing and coughing. He now felt listless and breathless and had an irritating nonproductive cough. His doctor stated that there had been no pyrexia.

The past history included no illness of note, and, in particular, no chest illness or symptoms, but the family history revealed that five years ago a sister had spent a year in a sanatorium.

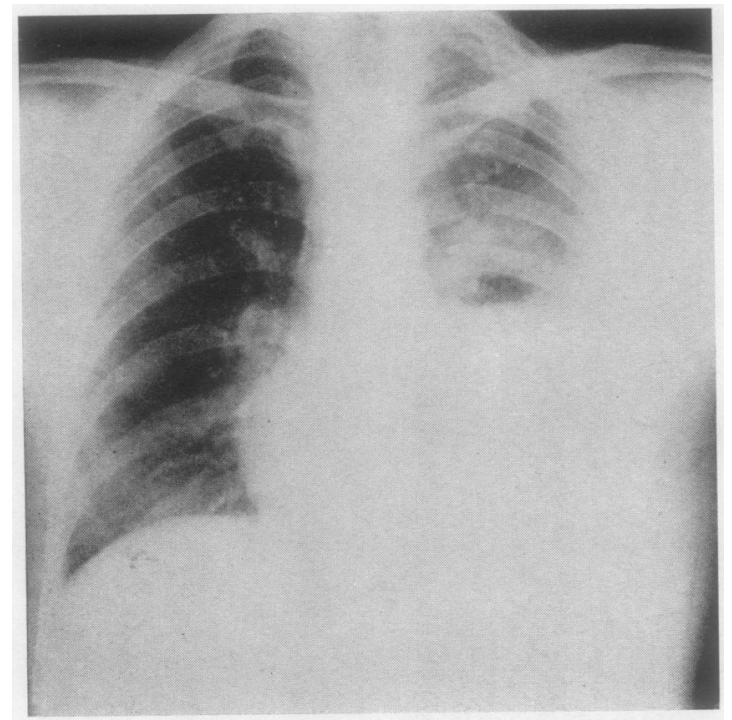

FIG. 4.-Case 2. Radiograph on August 26, 1952, showing recurrence of left-sided effusion preceding the aspiration of a further $1 \frac{1}{2}$ pints of haemorrhagic fluid and the instillation of "varidase."
On physical examination he was pallid, but showed no venous congestion or distress. The respiratory system showed the classical signs of a moderate leftsided pleural effusion, including displacement of the trachea to the right. The pulse was regular at a rate of 82 per minute and of moderate volume, while the rest of the cardiovascular system was also normal, apart from a rather low diastolic pressure (130/60 $\mathrm{mm}$. $\mathrm{Hg}$ ). The other systems were normal.

Initial investigations revealed a haemoglobin level of $88 \%$, a normal total and differential white blood count, and an E.S.R. of $42 \mathrm{~mm}$. (Westergren) in one hour. The radiograph of the chest showed a left-sided pneumothorax with effusion and associated partial collapse of that lung. Immediate diagnostic thoracentesis produced $8 \mathrm{oz}$. of fluid rese mbling venous blood. This showed $59 \%$ haem.oglobin, an erythrocyte count of $2,760,000$ per c.mm., and a leucocyte count of 3,600 per c.mm. (polymorphonuclears, $17 \%$; lymphocytes, $70 \%$; eosinophils, $13 \%$ ) compared with the concurrent peripheral blood count of 89 ", haemoglobin, an erythrocyte count of $4,200,000$ per c.mm., and a leucocyte count of 7,900 per c.mm. (polymorphonuclears, $60 \%$; lymphocytes, $33 \%$; eosinophils, $5 \%$; monocytes, $2 \%$ ). The radiographic appearances of the chest remained unchanged. Next day (August 9), despite frequent attempts at aspiration, only $2 \mathrm{oz}$. of fluid was removed, but four days later 1 pint of haemorrhagic fluid was withdrawn and the radiograph now showed that the left lung had almost completely re-expanded, although a small effusion persisted. The aspirated fluid contained $22 \%$ haemoglobin and 830,000 per c.mm. of red cells.

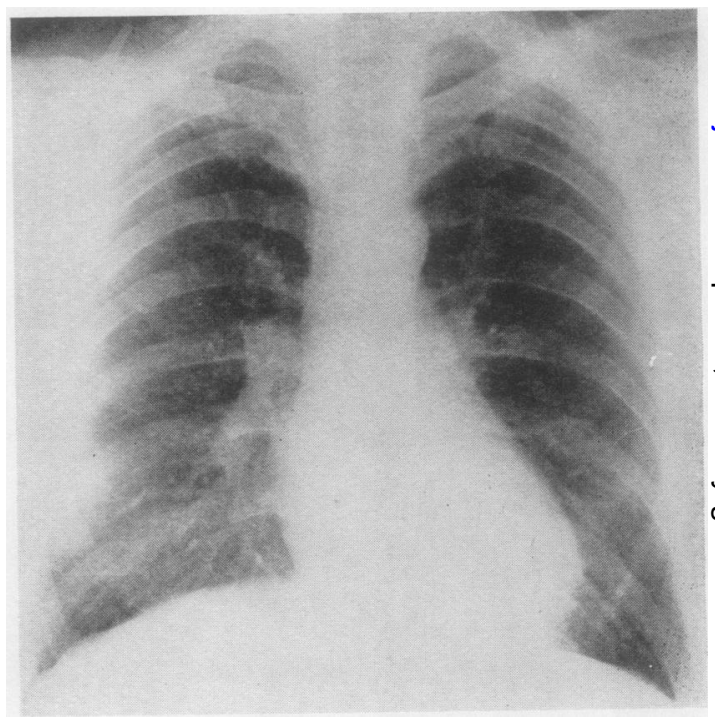

FIG. 5.-Case 2. Radiograph on October 15, 1952, a fortnight after discharge from hospital. No residual effusion. 
Up to August 26 there was evidence of recurrence of the effusion (Fig. 4). This refractory phase, coupled with evening pyrexia to about $100^{\circ} \mathrm{F}$., prompted further aspiration, when $30 \mathrm{oz}$. of xanthochromic, relatively acellular fluid was withdrawn. This fluid had a protein concentration of $4.9 \mathrm{~g} . \%$ and a bilirubin level of $1.7 \mathrm{mg} . \%$. This aspiration was immediately followed by the instillation of "varidase" (200,000 units of streptokinase and 50,000 units of streptodornase, dissolved in $10 \mathrm{ml}$. of physiological saline) into the pleural cavity. During the next 48 hours the patient felt further distress. There was a recurrence of chest pain, breathlessness, perspiration, pyrexia $\left(100-102^{\circ} \mathrm{F}\right.$ ), a tachycardia $(90-110$ per minute), a leucocytosis of 13,100 per c.mm. (polymorphs $90 \%$, lymphocytes $10 \%$ ), and increased effusion. On August 27 a pint of clear, relatively cellfree fluid was aspirated. Its bilirubin level was 0.15 mg. \%. Uneventful progress ensued. Further thoracenteses were unproductive. By September 17 the chest radiograph revealed only partial collapse of the left lung, associated with a small effusion.

On October 3 he was discharged home, feeling fit and regaining weight. Follow-up has shown virtually a complete recovery, for the serial chest radiographs have appeared normal since the film of October 15 (Fig. 5). He resumed work one month after discharge. $\mathrm{He}$ had then gained a further $7 \mathrm{lb}$. in weight. No evidence of pulmonary tuberculosis was obtained from the radiological investigations or sputum (four separate specimens were examined). The Mantoux test was positive to a 1 in 1,000 dilution.

CASE 3.-F. C., a housewife, aged 40, was admitted here on June 22, 1953, for the treatment of a recurrent compound ganglion on the dorsum of the wrist with a

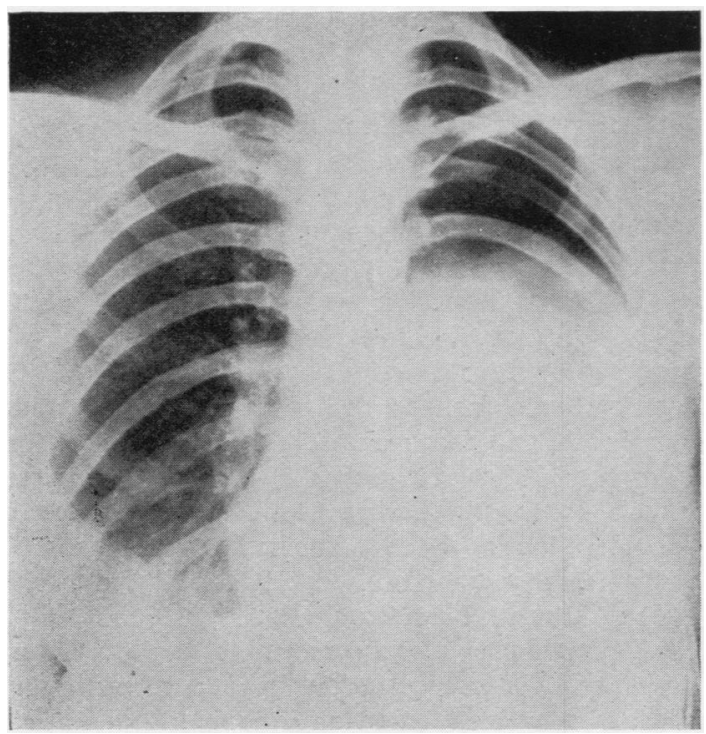

Fıg. 6.-Case 3. Radiograph on August 14, 1953. a large injtial left-sided pleural effusion before thoracentesis was begun, but no mediastinal displacement. course of combined streptomycin and P.A.S. An identically located ganglion had been excised two years previously and it revealed typical melon-seed bodies with the histological appearance of tuberculosis.

Apart from three attacks of rheumatic fever in childhood, producing no subsequent evidence of cardiac disease, she had no previous illnesses of note. Although there was a strong family history of tuberculosis, her frequent serial chest radiographs and erythrocyte sedimentation rates had always been normal. In particular, the lung ap:ces remained clear.

Physical examination showed no striking signs apart from facial pallor, koilonychia, and the ganglion. Her blood pressure was $140 / 80 \mathrm{~mm}$. $\mathrm{Hg}$. A blood count revealed haemoglobin $73 \%$, erythrocyte count of 3,600,000 per c.mm., mean cell diameter $7.2 \%$, and a leucocyte count of 14,000 per c.mm. with a normal differential count. The mean E.S.R. was $9 \mathrm{~mm}$. in one hour. On August 10, 1953, the ganglion was excised and again it contained typical melon-seed bodies.

On August 13 her temperature rose to $99^{\circ} \mathrm{F}$., while she experienced left-sided pleuritic pain, unaccompanied by a pleural rub or an effusion. The following afternoon she suddenly became shocked and dyspnoeic with a moderate left-sided pleural effusion. The mediastinum was not displaced (Fig. 6). The relatively sudden onset of a large pleural effusion and pallor immediately suggested a diagnosis of haemothorax. This was promptly confirmed by the aspiration of apparently pure blood with a haemoglobin value of $62 \%$. Moderate shock was shown by free perspiration, a pulse rate of 120 per minute, and hypotension $(80 / 40 \mathrm{~mm}$. $\mathrm{Hg})$. A half-hourly pulse

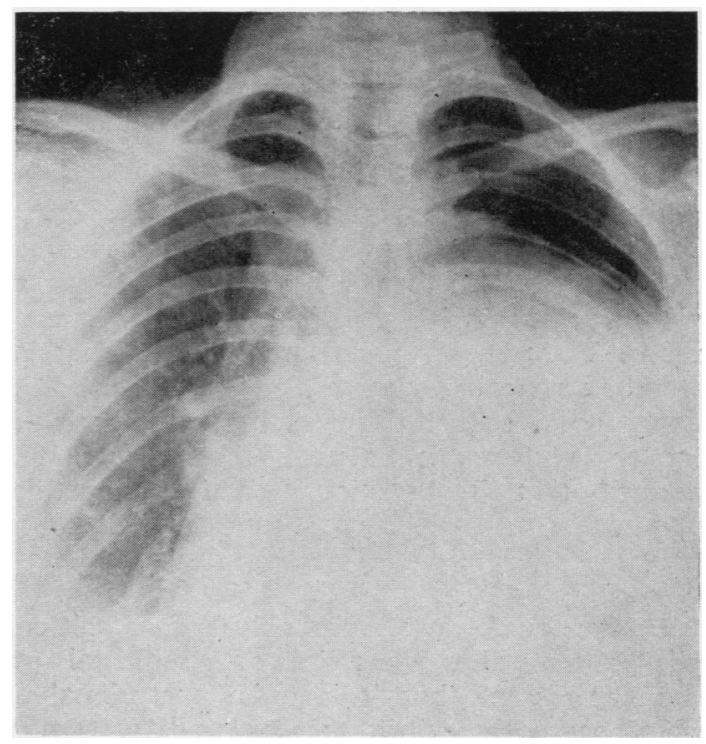

Fig. 7.-Case 3. Radiograph on August 15, 1953, three hours before death. The radiograph resembles Fig. 6 , but there is now mediastinal shift. 
and blood pressure chart was now begun and a blood transfusion set up. By 10 a.m. next day (August 14) her haemoglobin level was only $64 \%$, despite the administration of 4 pints of blood and 1 pint of plasma. The blood pressure was now $120 / 80 \mathrm{~mm}$. $\mathrm{Hg}$, but the pulse rate had increased to 140 per minute. Therapeutic thoracentesis was now begun, but after the aspiration of 2 pints of sanguineous fluid the patient demanded a respite. Meanwhile blood transfusion was continued; a further 5 pints of blood were at hand.

By 2.30 p.m. the blood pressure was $140 / 85 \mathrm{~mm}$. $\mathrm{Hg}$, with the pulse rate still 140 per minute, but rose to 150 per minute by 4 p.m. The blood pressure was unchanged. The chest radiographs (Fig. 7) now showed mediastinal shift to the right with a persistent large pleural effusion. Respiratory distress continued without signs of cerebral anoxia. Just before further aspiration at 4.30 p.m. there was a sudden general deterioration. The blood pressure dropped abruptly to $110 / 60 \mathrm{~mm}$. $\mathrm{Hg}$, and the pulse was thready and its rate was uncountable. A further 2 pints of the haemorrhagic fluid were promptly aspirated, but a syncopal attack precluded further immediate thoracentesis. At 5 p.m. she lapsed into extreme respiratory distress, accompanied by restlessness, disorientation, and delirium. The pupils were now large and reacted only sluggishly to light. As an arterial transfusion was being set up the patient died at 5.30 p.m.

Necropsy revealed $2 \frac{1}{2}$ pints of partly clotted blood in the left pleural sac, while the underlying lung was completely collapsed. A stretched and torn apical pleural adhesion with a bleeding point was located between the necks of the first and second ribs. The lungs showed no evidence of tuberculosis. It was concluded that the haemopneumothorax had resulted from the spontaneous tear of an old tuberculous pleural adhesion.

\section{Discussion}

The main aspects of spontaneous haemopneumothorax will now be reviewed.

Terminology, Aetiology, and Pathology.Hansen (1949) preferred the term "pneumohaemothorax," as the primary event is the intrapleural extravasation of air, followed by haemorrhage. The terms "spontaneous" or "idiopathic" may be erroneous (Cummer, 1915) as this condition could be a sequel to previous tuberculosis, no longer demonstrable. Indeed, Parkes Weber (1931) averred that "tuberculous" and "idiopathic" pneumothorax or haemopneumothorax differed only in that in the "idiopathic" type the tuberculous lesion was healed. Most cases of the "spontaneous" variety probably have occult congenital anomalies or relics of subpleural pulmonary disease, but it is quite exceptional for pulmonary tuberculosis to develop later (Louria, 1938 ; Hyde and Hyde, 1951).
Pleural adhesions are often observed in routine $\overrightarrow{\overrightarrow{\vec{c}}}$ necropsies even where there is no previous history $\overrightarrow{0}$ or concurrent evidence of lung infection (Leopold 흐 and Lieberman, 1935). The contributory role of $\overline{\frac{}{5}}$ such supposed exciting causes as straining, cough- $\mathbb{Q}$ ing, sneezing, and yawning is undetermined. They may be absent (Louria, 1938). A spontaneous pneumothorax first develops and its various mech-. anisms have been critically discussed (Kjaergaard, $\vec{\omega}$ 1932 ; Perry, 1939). Air escapes intrapleurally ${ }_{\mathscr{S}}$ following the rupture of a valve-vesicle or an $\vec{x}$ emphysematous bulla. An alternative view is that of Macklin and Macklin (1944), who produced pneumothorax and haemopneumothorax in experimental animals by the initial induction of pul- + monary interstitial emphysema. They postulated that this might occur in man, following the intra- $\vec{z}$ pulmonary rupture of alveoli with air, then dissecting subpleurally along the interstitial tissues to $\frac{\widehat{S}}{\mathcal{S}}$ leak through the visceral or mediastinal pleura $\vec{\theta}$ into the pleural cavity. This subject has been dis- $f$ cussed in detail (Solovay, 1949).

The accepted explanations incriminate rupture of both subpleural bullae and adhesions, the former allowing the escape of air and the latter blood into the pleural cavity. The exact source of bleeding has rarely been demonstrated (Hartzell, $\propto$ 1942 ; Helwig and Schmidt, 1947 ; Cuningham, $\overrightarrow{\vec{O}}$ 1950). Pleural adhesions are torn by the traction 3 of the expanding pneumothorax, and in the case? of massive haemothorax, at least, the haemorrhage? is believed to come from the parietal end of a severed pleural adhesion (Hartzell, 1942), which is supplied by the intercostal vessels and is indepen-x dent of the haemostatic influence of the accompanying pulmonary collapse.

Both subpleural bullae (Pardel and Mazzei, $\frac{\delta}{3}$ 1934) and pleural adhesions (Helwig and Schmidt, 1947) can be highly vascularized. Since Pitt (1900) first reported a torn emphysematous bulla attached to a fibrous adhesion, other authors (Hopkins, 1937; Hartzell, 1942) have either produced evi N dence of or have directly observed (Hansen, 1949) haemorrhage from a torn bulla. Yet others (Davidson and Simpson, 1940 ; Arst, Lahey, and Kunkel, 1950 ; Irwin, 1951) have shown that vessels in torn adhesions can be the source of haemorrhage or have witnessed this at thoraco tomy (Beatty and Frelick, 1952; Myers et al: 1951 ; Ross, Dugan, and Farber, 1953), wher 5 the appearances closely resemble the occasiona $\omega^{\circ}$ haemorrhagic complication in the operation of thoracotomy with division of pleural adhesion? (Sellors, 1951). 
Although other relevant observations on haemothorax can only be briefly cited, it is worth recalling that Hart and Jones (1947) record this as a sequel to aberrant lung tissue, while Crawford and Shafar (1946) considered that haemothorax might follow the spontaneous rupture of a pleural adhesion during sudden muscular movement. Again, two of Hansen's three cases (1949) of spontaneous haemopneumothorax had cystic disease of the lungs, an association which had not then been reported, but is also apparent on the affected side in our first case (Fig. 3).

Intrapleural blood clots rapidly and this explains the frequent absence of coagulation in vitro of such pleural aspirates (Cosgriff, 1950). The natural history of haemothorax has been reviewed recently (Harold, 1951). This effusion remains fluid because of the defibrinating action of the cardiorespiratory movements, while fibrin is deposited on the pleural surfaces. Melick and Spooner (1945) showed in experimental animals that intrapleural clotting recurs if further fibrinogen is added. Blood in the pleural space acts as an irritant, provoking a large serous effusion (Sellors, 1945) which dilutes the sanguineous fluid present. Secondary clots may occur several days later due to an increased concentration of fibrinogen. Large gelatinous masses of bloody fibrin may laminate the parietal pleura and be followed quickly by angioblastic and fibroblastic proliferation, extending into the clot from the pleura, which itself remains as a thin, translucent membrane (Moore, 1949). This fibrothorax, sometimes accompanied by loculation, is disabling (Smithy, 1943) and characterized by impaired lung expansion from a flattened hemithorax of approximated ribs with secondary scoliosis, described as the "frozen" or "fixed" chest (Sellors', 1951).

Clinical Syndrome and Prognosis.-Our three cases typify the remarkably clear clinical picture, which resembles that of spontaneous pneumothorax but with varying additional evidence of haemorrhage and pleural effusion. The patient, with previous good health, although sometimes underweight (Hyde and Hyde, 1951), is usually a male of 15 to 45 , frequently in the third decade. During mild activity, or sometimes while at rest, he is seized with a sudden, sharp, stabbing unilateral pain in the anterior, or occasionally posterior, chest. This pain is increased by movement and may radiate to the shoulder or abdomen and often subsides within 24 hours, only to return. The pain may be confined to the abdomen (Fusia and Cook, 1952). Irritation of the diaphragmatic pleura may produce signs simulating an acute abdominal emergency, especially if there are wellmarked signs of shock, while nausea, vomiting, and even abdominal rigidity may further mislead (Rolleston, 1900 ; Hurxthal, 1928 ; Milhorat, 1931 ; Waring, 1945 ; Crimm, 1948 ; Hansen, 1949 ; Deiss, Gale, and Brown, 1950), even to the extent of leading to laparotomy (Fischer, 1922 ; Fusia and Cook, 1952; and Ross, 1952). It may simulate appendicitis (Milhorat, 1931 ; Jones and Gilbert, 1936), gall-bladder disease (Hurxthal, 1928 ; Frey, 1935), bleeding peptic ulcer (Irwin, 1951), or perforated peptic ulcer (Rolleston, 1900 ; Fischer, 1922). Again, the pain may suggest coronary thrombosis (Castex and Mazzei, 1936; Rist and Worms, 1940 ; Sloer, 1939 ; Hansen, 1949), and if there is electrocardiographic evidence of myocardial ischaemia, as in Case 1 , further confusion in diagnosis might arise. Thus, in the older patient, a dissecting aneurysm of the aorta with subsequent haemothorax might well be wrongly suspected. Coexistent haemoptysis has occasionally been described (Szenes, 1929; Groen and Godfried, 1948). As in Case 2, an eosinophilia of the blood in both the circulation and the effusion has occasionally been described (Troisier, Bariéty, and Dugas, 1936 ; Groen and Godfried, 1948 ; Deiss et al., 1950 ; Hyde and Hyde, 1951). Complate recovery from spontaneous haemopneumothorax is usual within two months, but death from relentless haemorrhage is always a danger within the first three days. A late fatality may result from large fibrinous deposits (fibrothorax) as described by Jones and Gilbert (1936). Slight pyrexia, leucocytosis, and a raised erythrocyte sedimentation rate are common accompaniments of spontaneous haemopneumothorax.

TREATMENT.-The intrapleural haemorrhage frequently stops within the first three days. Such cases respond to bed rest, sedation, oxygen inhalation, antibiotic therapy, adequate blood transfusion, and early repeated and complete evacuation of blood and air from the pleural cavity. Experience in the management of chest wounds during and since World War 2 has led to a radical alteration in the treatment of haemothorax (Sellors, 1945 ; Tuttle, Langston, and Crowley, 1947). It was previously considered that thoracentesis should be delayed or, if adopted, that it should be accompanied by air replacement. This latter procedure is both useless (Fusia and Cook, 1952) and even a hindrance to early recovery (Sellors, 1951). It has been pointed out (Sellors, 1945) that immediate and repeated aspiration, although decreasing the intrapleural pressure, does not restart bleeding and will prevent a later fibrothorax. There is no evidence 
(Fusia and Cook, 1952) that properly administered blood transfusion incites further haemorrhage. Moser and his colleagues (1951) described four cases responding to these measures, while Hyde and Hyde (1951) had similar success in 11 out of 12 cases, with the remaining patient requiring late decortication. In Case 1, which had syncopal attacks on admission, the adoption of conservative treatment, not including blood transfusion, sufficed to produce a speedy recovery.

Melick and Spooner (1945) have shown that haemothorax may be followed within five days of its onset by fibroblastic proliferation, which in turn leads to organization and the formation of a "peel" on the contracted lung surface. This sequence can now be prevented by enzymatic debridement following the intrapleural injection of fibrinolytic enzymes (Sherry, Tillett, and Read, 1950 ; Read and Berry, 1950 ; Carr and Robbins, 1951 ; Miller, Ginsberg, Lipin, and Long, 1951 ; Ross, 1952 ; and Jones and Bigham, 1953) in those patients in whom aspiration is indicated, but has proved unsuccessful and haemorrhage has stopped.

Combinations of streptokinase (S.K.) and streptodornase (S.D.) have usually been employed, but more recently other workers (McCroskey and Hardin, 1953; Delannoy and Ribet, 1953) have used trypsin with equal success. Ross (1952) advocates that aspiration of the blood should be followed by instillation of these enzymes, allowing them to remain in situ for only six to eight hours. Then complete aspiration of the residual enzyme solution should be carried out, using irrigation with physiological saline, if necessary. Repeated injections, employing several sites, may be required. This treatment is applicable to those patients who are liable to prolonged convalescence because of dense fibrin deposits or clotted haemothorax. Indeed, this fibrinolytic therapy may prevent subsequent decortication (Read and Berry, 1950 ; Beatty and Frelick, 1952), although the former is no substitute for the latter (Carr and Robbins, 1951).

Streptokinase liquefies fibrinous exudates and blood-clots, thus exerting mainly a fibrinolytic action (Christensen and MacLeod, 1945; Tillett, 1952), while streptodornase acts only on the nucleoproteins of the degenerate cells in the exudate (Tillett, Sherry, and Christensen, 1948). Neither enzyme is harmful to healthy cells, while both enhance phagocytosis (Johnson, 1950), thus acting synergistically with antibiotics. Aspiration of the lysed fluid is an important part of the procedure, while trypsin cannot be usefully combined with the other enzymes as it destroys streptokinase. This enzymatic treatment proved valuable in Case 2 which had, however, an associated febrile response with pleuritic pain, as Carr and Robbins (1951) had described in six of their 10 cases of clotted haemothorax so treated.

Three reactions may accompany the use of S.D. and S.K. instillations. First, a local effusion with living polymorphonuclear leucocytes. Secondly, $\overrightarrow{\vec{\omega}}$ a pyrogenic reaction, with the initial rise of tem- ${ }^{\circ}$ perature occurring about six hours later and be- $\overrightarrow{\overrightarrow{2}}$ coming maximal in 24 hours, provided that the enzymes and lysed material are not evacuated sooner. The febrile reaction is usually accompanied by headache, nausea, malaise, and arth- $\$$ ralgia, but these symptoms usually respond to 의 aspirin administration. Thirdly, and rarely, since $\vec{r}$ both S.D. and S.K. are antigenic, allergic reactions involving the periorbital tissues may result. In the case of trypsin, slight histaminic reactions may occur, manifest by pyrexia, hypotension, and tachy- $\vec{E}$ cardia, but neutralized by antihistaminics. Caution is required during fibrinolytic enzyme therapy to avoid an injection directly into a blood-vessel, while the pyrexial reactions may wrongly suggest that further haemorrhage is occurring.

Massive, uncontrolled intrapleural haemorrhage $\stackrel{\mathbb{D}}{\perp}$ is a surgical, rather than a medical, emergency. $\overrightarrow{\vec{F}}$ Early thoracotomy is often indicated to identify $\frac{3}{3}$ and either ligate or electro-coagulate the bleeding point as a life-saving procedure. Hansen (1949) first undertook this measure, but he was unfortunate enough to observe multiple torn emphysema- 음 tous bullae which were too extensive for suture. $\underset{x}{x}$ Other workers (Deucher, 1949 ; Myers et al., 1951 ; $\dot{\sigma}$ Beatty and Frelick, 1952 ; Holloway, Speir, and Sadler, 1952 ; Ross, 1952 ; Ross et al., 1953 ; ̊̊ Borrie, 1953) demonstrated its value. Indeed, in 3 the patient described by Myers and his colleagues 0 (1951) the intrapleural bleeding was estimated to exceed 5 litres. This operation permits the simul-o taneous removal of the blood-clot, and the recovery phase may thus be reduced from months to weeks. On The bleeding point may not, however, be identified $N$ (Harold, 1951). This is hardly surprising as స్ట identification of the source of haemorrhage has 0 frequently not been possible in cases submitted to necropsy. We considered resort to thoracotomy in $\frac{0}{\Phi}$ our third case, but its deferment beyond the first $\stackrel{\circ}{+}$ few hours from the onset left us virtually with a 0 moribund patient, in whom simple thoracentesis

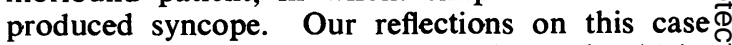
led us to conclude that more emphasis should be $\vec{\Phi}$ placed on the pulse rate than on the blood pressure as an index for immediate surgery. Thus, when 
the pulse rate rose above 120 per minute and mediastinal displacement was manifest we had over-delayed resort to remedial thoracotomy, despite a normal blood pressure. The abrupt deterioration in this patient was especially surprising as she was the only patient presenting without mediastinal shift.

Finally, for those patients who fail to benefit from enzymatic instillation, thoracotomy with pulmonary decortication (pleurectomy) is now the established procedure (Elrod and Murphy, 1948 ; Hansen, 1949 ; Deiss et al., 1950 ; Seley and Neuhof, 1951 ; Carroll, McClement, Himmelstein, and Cournand, 1951; Hyde and Hyde, 1951; Kiekens, 1952 ; Eidinger and Rubin, 1952 ; Fusia and Cook, 1952) to prevent extensive fibrinous deposits on the pleural surface, a calcified pleura (Milhorat, 1937), cor pulmonale, and spinal deformities. Pulmonary decortication, however, may lead to other complications such as further haemorrhage, air embolus, or bronchopleural fistula (Deucher, 1949). Carroll and his colleagues (1951) used this technique in nine cases of haemothorax, two of which were of the spontaneous variety. Of these two patients, one derived great benefit, while the other showed only slight improvement in lung function. He concluded that operative success may occur even without much associated clinical relief. Kiekens (1952), on the other hand, claimed that this operation was of great value.

\section{SumMary AND CONCLUSIONS}

The literature on spontaneous haemopneumothorax, comprising some 150 cases, is surveyed. The aetiology, differential diagnosis, and recent therapeutic trends are outlined. This complication of spontaneous pneumothorax merits wider recognition as a potentially grave emergency. The fatality rate is $15 \%$.

Three recently observed cases are described. All had frequent and early thoracenteses. The first patient responded to conservative measures without resort to blood transfusion; the second required blood transfusion and, later, enzymatic pleural debridement; the third had continued intrapleural haemorrhage requiring repeated blood transfusions, but towards the end of the first 24 hours even simple thoracentesis induced syncope. She died before arterial transfusion was begun while unfit for remedial thoracotomy. Retrospective consideration compels the belief that increasing tachycardia despite normal blood pressure warrants immediate thoracotomy in such cases.
We are indebted to Dr. H. H. Kenshole, H. M. Coroner, for permission to publish the third case, and to Dr. Keith Simpson (Guy's Hospital) and Mr. Geoffrey Flavell (London Hospital) for criticism of our manuscript.

\section{REFERENCES}

Arst, D. B., Lahey, W. J., and Kunkel, P. (1950). Ann. intern. Med., 33, 718 .

Beatty, G. A., and Frelick, R. W. (1952). Ibid., 36, 845.

Borrie, J. (1953). Brit. med. J., 2, 16.

Carr, D., and Robbins, S. G. (1951). Ann. Surg., 133, 853.

Carroll, D., McClement, J., Himmelstein, A., and Cournand, A., (1951). Amer. Rev. Tuberc., 63, 231.

Castex, M. R., and Mazzei, E. S. (1936). Presse méd., 44, 2097.

Chapman, J. S. (1950). In Principles of Internal Medicine, p. 1401. Ed. by T. R. Harrison. Blakiston Co., New York.

Christensen, L. R., and MacLeod, C. M. (1945). J. gen. Physiol., $28,559$.

Cosgriff, S. W. (1950). Amer. J. Med., 8, 57.

Crawford, A. M., and Shafar, J. (1946). Brit. med. J., 1, 88.

Crimm, P. D. (1948). J. thorac. Surg., 17, 662.

Cummer, C. L. (1915). Amer. J. med. Sci., 150, 222.

Cuningham, J. A. K. (1950). N.Z. med. J., 49, 708.

Davidson, M., and Simpson, C. K. (1940). Lancet, 1, 547.

Deiss, W. P., Gale, J. W., and Brown, J. W. (1950). Amer. Rev. Tuberc., 62, 543.

Delannoy, E., and Ribet, M. (1953). Presse méd., 61, 97.

Deucher, F. (1950). Helv. chir. Acta, 17, 170.

Dorset, V. J., and Terry, L. L. (1949). Amer. J. Med., 6, 135.

Eidinger, S. L., and Rubin, E. H. (1952). Canad. med. Ass. J., 67, 43.

Elrod, P. D., and Murphy, J. D. (1948). J. thorac. Surg., 17, 401.

Fischer, B. (1922). Z. klin. Med., 95, 1.

Freund, J., and Hicks, H. R. (1953). Va med. Mon., 80, 162.

Frey, J. L. (1935). J. Amer. med. Ass., 104, 1395.

Fusia, D. A., and Cook, W. L. (1952). Amer. Rev. Tuberc., 65, 744.

Goldman, A., and Roth, H. (1944). Ann. intern. Med., 21, 1011.

Groen, A. S., and Godfried, E. G. (1948). Ned. T. Geneesk., 92, 3393.

Hansen, J. L. (1949). Acta med. scand., 132, 517.

Harold, J. T. (1951). Thorax, 6, 162.

Harrell, C. L. (1949). Va med. Mon., 76, 167.

Hart, F. D., and Jones, A. C. (1947). Lancet, 2, 722.

Hartzell, H. C. (1942). Ann. intern. Med., 17, 496.

Helwig, F. C., and Schmidt, E. C. H. (1947). Ibid., 26, 608.

Holloway, J. B., Speir, R. C., and Sadler, R. N. (1952). Amer. Surg., $18,518$.

Hopkins, H. U. (1937). Amer. J. med. Sci., 193, 763.

Hurxthal, L. M. (1928). New Engl. J. Med., 198, 687.

Hyde, L., and Hyde, B. (1951). Amer. Rev. Tuberc., 63, 417.

Irwin, H. R. (1951). Med. Bull. Europ. Command, 8, 538.

Johnson, A. J. (1950). J. clin. Invest., 29, 1376.

Jones, O. R., and Gilbert, C. L. (1936). Amer. Rev. Tuberc., 33, 165.

Jones, P. N., and Bigham, R. S., Jr. (1953). Ann. intern. Med., 39, 907.

Kiekens, R. (1952). Acta chir. belg., 51, 172.

Kjaergaard, H. (1932). Acta med. scand., Suppl. 43.

Knight, F. L., and Oelrich, A. M. (1949). N. C. med. J., 10, 375.

Leopold, S. S., and Lieberman, L. M. (1935). Ann. intern. Med., 9, 19.

Louria, M. R. (1938). Quart. Bull. Sea View Hosp., 4, 44.

McCroskey, C. E., and Hardin, C. A. (1953). Arch. Surg., Chicago, 66,650 .

Macklin, M. T., and Macklin, C. C. (1944). Medicine, 23, 281.

Melick, D. W., and Spooner, M. (1945). J. thorac. Surg., 14, 461.

Milhorat, A. T. (1931). Amer. J. Surg., 13, 315.

(1937). Amer. Rev. Tuberc., 35, 106.

Miller, J. M., Ginsberg, M., Lipin, R. J., and Long, P. H. (1951). J. Amer. med. Ass., 145, 620.

Moore, J. A. (1949). Sth Surg., 15, 255.

Moser, M. (1951). Dis. Chest, 19, 339. 
Myers, R. T., Johnston, F. R., and Bradshaw, H. H. (1951). Ann. Surg., 133, 413.

Nalls, W. L., and Matthews, J. H. (1949). Dis. Chest, 15, 612.

Nario, C., Bermúdez, O., and Espasandin, J. (1949). Arch. urug. Med., 35, 303.

Pardal, R., and Mazzei, E. S. (1934). Paris méd. (partie méd.), 93, 509.

Perry, K. M. A. (1939). Quart. J. Med., 8, 1.

Pitt, G. N. (1900). Trans. clin. Soc. Lond., 33, 90.

Read, C. T., and Berry, F. B. (1950). J. thorac. Surg., 20, 384.

Repetti, L. P. (1940). Semana méd., B. Aires, 2, 1186.

Rist, E., and Worms, R. (1940). Bull. Soc. méd. Hôp. Paris, 56, 272.

Rolleston, H. D. (1900). Trans. clin. Soc. Lond., 33, 90.

Ross, C. A. (1952). J. thorac. Surg., 23, 582.

Ross, J., Dugan, D., and Farber, J. E. (1953). Dis. Chest, 23, 577.

Rottenberg, L. A., and Golden, R. (1949). Radiology, 53, 157.

Rusby, N. L. (1947). British Encyclopaedia of Medical Practice. Interim Suppl., No. 60, p. 10. Butterworth, London.

Seley, G. P., and Neuhof, H. (1951). J. thorac. Surg., 21, 600.

Sellors, T. H. (1945). Lancet, 1, 143.

- (1951). British Encyclopaedia of Medical Practice, 2nd ed., vol. 6, p. 177. Butterworth, London.

Sherry, S.. Tillett, W. S., and Read, C. T. (1950). J. thorac. Surg., $20,393$.

Sloer, M. (1939). Rev. med. Rosario, 29, 575.

Smithy, H. G. (1943). J. thorac. Surg., 12, 338.

Solovay, J. (1949). Radiology, 53, 256.

Szenes. A. (1929). Arch. Gynäk., 136, 600.

Tillett, W. S. (1952). Harvey Lect. Series 45 (1949-50), p. 149. C. C. Thomas, Springfield, Illinois.

- Sherry, S., and Christensen, L. P. (1948). Proc. Soc. exp. Biol., N.Y., 68, 184.

Towson, R. T. (1954). Canad. med. Ass. J., 70, 188.

Troisier, J., Bariéty, M., and Dugas, J. (1936). Bull. Soc. méd. Hôp. Paris, 52, 984.
Tuttle, W. M., Langston, H. T., and Crowley, R. T. (1947). J. thorac. Surg., 16, 117.

Waring, J. J. (1945). Clinics, 4, 940.

Weber, F. P. (1931). Brit. med. J., 2, 989.

\section{POSTSCRIPT}

A fourth case of spontaneous haemopneumo- क thorax was treated recently by one of us (R. J. C.). $\vec{\circ}$

J.W., a motor mechanic aged 27 , was admitted to the Royal Victoria Hospital, Boscombe, on October 2, $\vec{\omega}$ 1954. At work that morning he suddenly felt an acute, left-sided sub-mammary pain, worse on move- $\overrightarrow{\vec{x}}$ ment and deep breathing, and radiating to the left clavicular and scapular regions. On admission to hospital a few hours later he had signs of a moderate left-sided pleural effusion with mediastinal displace- $f$ ment to the right. He was pallid, but the pulse rate $\subseteq$ and blood pressure were normal.

The clinical impression of haemopneumothorax was supported by a radiograph of the chest and was confirmed by thoracentesis. A single slow aspiration of 3 pints of sanguineous fluid was carried out. No further treatment was adopted. The haemoglobin concentration of the effusion was $76 \%$, compared with $72 \%$ in the peripheral blood. A week later the radiograph of the chest was normal. Subsequent progress was uneventful. He was discharged from hospital on October 30 and began work again one month later. 